patients from white-lead works and similar manufactorics, where the fine dust from lead preparations is gradually worked into the exposed parts of the skin, and is difficult of removal. The effect of baths of alkaline sulphides, however, proves that absorlved lead may be deposited in the skin, and that the metal in the tissues is, to a certain extent, in a soluble form. Such a bath discolors various parts of the body, but not uniformly. The color is sometimes nearly black. When the sulphide of lead formed on the skin has been removed by repcated washing with soap and water, the brown color is stated to be again and arain obtained by repeating the sulphuretted bath at intervals of a few days; showing that when the lead is removed from the skin, a new portion is brought out from the interior. I have not had an opportunity of observing the effect of a repeated use of the sulphuretted bath, but it would seem that an appreciable amount of lead can be thus eliminated.

I find, from the recently published book of Dr. Thudichum, on the Pathology of the Urine, that Kletzinsky has noticed the very minute amount of lead eliminated by the urine. In fourteen cases of distinct lead poisoning, in which the urine of a whole day was analyzed, Kletzinsky succeeded in two ouly in proving the presence of the metal. In the others, only a doubtful indication was obtained. In a well-marked case in London, under the use of ten grains of iodide of potassium three times a day, Dr. Bernays twice failed to find lead in the urine of twelvo hours; but after administering iodido of potassium for ten days, it was present in sufficient quantity to give a copious precipitate with sulphuretted hy. drogen, in the solution obtained by evaporating the urine nearly to dryness and dissolving the residue in aqua regia.

It is evident that iodide of potassium, the most energetic agent known for removing absorbed lead from the system, is far less efficient in this respect than is gencrally believed.

\title{
CASE OF LITHOTOMY.
}

[Read at a meeting of the Fimira Academy of Medicine, August 2A, 1868, and communloated for the Boston Medlcal and Surgical Journal.]

BY W. C. WEY, M.D., ELMIRA, N. Y.

IN 1856, Henry Smith, then 3 years old, a healthy, robust child, manifested symptoms which were supposed to proceed from the presence of ascarides in the rectum, though worms of that species had never been seen in his stools. He had frequent inclination to go to stool, strained severely while on the vessel, complained of itching and burning about the anus, and in a short time began to drag at the prepuce with his fingers, and to show signs of distress in the escape of urine. At a later period he passed water more frequently than was natural, and with an extreme degreo of pain. VoL. LX. $-22^{*}$ 
Still later, the discharge of urine became involuntary, so that his clothes and bed were always wet, and it scemed as if he had no power to control its expulsion, as soon as even a small quantity accumulated in the bladder. In this manner, from time to time relieved by treatment, he passed more than a year, when in September last, the presence of a stone was detected by a common gum-clastic catheter, as it was being withdrawn from tho bladder. Tho stone was clearly and distinctly felt on many occasions, and always on withdrawing the catheter, just before the beak of the instrument escaped from the viscus, thus leading to the impression that the situation of the calculus was in the anterior portion of that cavity, beneath the pubes. Several months afterward a sound was introduced, and the stone was delicately felt, as the instrument glided into the bladder, but it was readily impressed as the sound was being withdrawn. The operation of sounding was accomplished while the boy was under the influence of chloroform. Before, in using a catheter, it was always found necessary to overcome his stout resistance, by force, though he alleged he did not suffer pain in the operation. He evidently apprehended some more serious surgical interference.

The sound, after entering the bladder (and this was our subsequent experience), could be mored in two directions only: forward and backward. It could not be made to sweep around the bladder, but secmed to be held laterally, as if it had not yet penetrated completely within that cavity. The bladder appeared to be always empty, or, to speak moro correctly, it was every few minutes emptied of its contents. While the sound was being used, urine wonld be forced, by powerful straining, along the side of the instrument, and at the same tino prolapsus of the anus would occur. Prolapsus of the anus had existed with every movement from the bowels, and with most of the acts of urination, for eight months before the operation. The presence of the stone exciting the bladder to constant contraction, thus inducing a condensed and unyielding firmness of its walls, probably proved the reason why the sound had so little liberty of motion in a lateral direction. Considering the situation of the stone bencath the pubes, and its perfect immobility, no information of the least value could bo obtained respecting its size or shapo; and we were left wholly to conjecture as to these important peculiarities.

On the 15th of June last, the boy being then 5 years and 3 months old, I performed the lateral operation of lithotomy, assisted by Drs. Squier, J. F. Hart and Covell. Chloroform was administered, and the patient remained insensible until some time after the removal of the calculus. An incision, a trille over an inch in length, was made from the raphe of the perinæum, five or six lines above the margin of tho anus, obliquely downward and to the left, midway between the anus and the tuberosity of the ischium. The groave of the staff in the urethra was readily reached, 
and the scalpel was carried through the prostate gland into the bladder. Not more than a teaspoonful of urine escaped through the wound. The staff was then withdrawn, and, guided by the finger, a pair of common polypus forceps were conducted into tho bladder. After a little delay, the stone was felt, occupsing a position behind the pubes, and the blades of the forceps were made to grasp it. In the effort to extract, the calculus broke, and two small pieces were withdrawn. The calculus had now changed its situation, and by introducing a finger in the rectum to serve as a guide, the stone was grasped securely by the forceps, its axis corresponding with the direction of the wound, and after gentle, but persistent traction, aided by moving the handles of the forceps, perpendicularly and laterally, to enlarge the opening in the prostate, it was at length extracted. The bladder was washed out with warm water directed through a syringe, and $\mathrm{my}$ little finger made a careful exploration in search of another stone, but without finding one.

I endeavored, as nearly as possible, to follow the plain directions of Mr. Liston, in the successive steps of the operation.

The calculus, which is of the varicty known as the triple phosphate, or the ammoniaco-magnesian phosphate, weighed two hundred and forty urains. It was oval in shape, rough and shining on its external surface, and disposed to crumble or scale, but firm and dense within. It has hardened from exposure to the air.

A gum-elastic catheter was passed through the wound into the bladder, a portion cut off, leaving two inches of the tube projecting, and it was held in its proper situation by means of strings secured to a handkerchief, tied above the pelris.

Three hours after the operation, the boy had ferer, complained of pain in his head, was dizzy, and called for cold water. I as. cribed the pain and dizziness in his head to the influence of chloroform. Urine was flowing freely through the tube.

Three hours later, at 6 o'clock, P.M., his fever had abated, and moisture appeared quite generally upon the surface of the body; still he was clamorous for cold drinks.

June 16th, 8 o'clock, A.M.-Passed a quiet night, crying out twice with pain in the region of the bladder. Tongue moist, skin cool, urine abundant. He calls urgently for hearty food.

6 o'clock, P.M.-Has passed a comfortable day, without a trace of fever; bowels and whole abdominal surface free from tenderness. He turns from one side of the bed to the other without difficulty, and is eager to cat substantial food. Urine abundant, and some mucus is discharged with it.

17th, 8 o'clock, A.M.-Had a good night; slept more quietly and continuously than for months before. The bed is wet, from the escape of urine through the tube, and nearly forty-eight hours having elapsed since its introduction, it was withdrawn, and in a quarter of an hour urine passed in a freo stream through the ure- 
thra. The bowels not having moved since the morning of the operation, castor oil was given.

6 o'clock, P.M.-The oil had operated several times quite frec. ly; morphia in solution was given to check the discharges. He has occasional twinges of pain in the region of the bladder. In accordance with the recommendation of $\mathrm{Mr}$. Bransby Cooper, in cases of a like character, I allowed more generous diet; in fact, I advised tho attendants of the boy not to restrict him to any special diet, but to allow him whatever he called for, both to eat and to drink. Acting upon this sugrgestion, and to quiet his unceasing cries for hearty food, he ate a piece of boiled ham, with bread and butter and potatoes, and concluded the meal with strawberies. Urine escapes freely through the wound.

18 th, 8 o'clock, A.M.- - Slept well; carly in the morning urine escaped in a full stream through the urethra; urine is constantly escaping through the wound. Suffered no inconvenience in consequence of the increased allowance of food. Cries to sit at the table and take his meals with the family. Liberal diet continued. The wound looks well, discharges urine, and is beginning to secrete pus.

7 o'clock, P.M.-Still improving; during the absence of his mother for a moment, he got out of bed, ran to another room for water, and was in the act of climbing into bed when discovered. It is extremely difficult to confine him; so much so, that one person is compelled to sit beside the bed, to keep him from running about the house.

I will not detail his progress from day to day, as it would be tedious to listen to the record, particularly as no circumstances of importance occurred until the twelfth day, when, for the third time since the operation, urine escaped through the urethra again, and the wound quite suddenly closed. Forty-cjght hours after the operation, it will be remembered, a few minutes after withdrawing the tube from the bladder, he made water through the urethra. Again, twenty-four hours subsequently, he made water naturally, and not again until the twelfth day, when the flow of urine ceased wholly to take place through the wound, and passed in the natural chamel, at intervals varying from one to three or fire hours. During sleep it passed involuntarily until the night of the 6th of July, when the bladder was not emptied from the time of going to bed until early in the morning, on awakening from sleep. IDuring all this period of three weeks, he was inclined, whenever the desire to make water scized him, to take hold of the prepuce and pull violently upon it, whether in the sleeping or waking state. His bowels moved regularly every day after the third day from the operation, until the fourteentl or fifteenth day, when he was attacked with diarrhœa, which continued nearly a week, reducing him in strength and weight materially. While suffering from diarrhœa, prolapsus of the anus took place, but this condition sub- 
sided as snon as the discharges became natural again, and up to this time, July 14th, it has not returned. The boy appears now to be perfectly well.

After reading the above article, some discussion arose in the Academy, respecting the great rarity of calculons aflections in this section of the country. This case is remarkable chiefly, and perhaps only, because it is the first instance of stone in the bladder that has ever been presented to the notice of physicians now liv. ing in this vicinity. Doctor's Purdy, and E. L. Hart, the former of whom has since died, whose experience and practice in this county extend over a period of more than thirty years, had never met a like case; nor had they ever known of one in the practice of others among their associates, and it is to be presumed that this is the only example of vesical calculus that has ever had its origin in the County of Chemung.

A few years ago, Dr. Frank H. Hamilton, of Buffalo, addressed a circular to nearly all the physicians of this and the neighboring counties, making special inquiry relative to the frequency of cases of vesical calculi, within the field of their observation. Not a single instance was reported to him from this county; and in conversation with physicians from the various towns, I ascertained that such affections were wholly unknown in actual practice.

\section{LETTER FROM PARIS.}

[Communicated for the Boston Medical and Surgical Journal.]

Audible Knockings of the Muscles-Idiopathic Tetanus-Dislocation of the Hip-Joint, unveduced for six months-Removal of the Entirs Tongue-Operation for Vesico-Vaginal Fistula.

AT a recent meeting of the "Académie des Sciences," M. Jobert de Lamballe read a paper, the subject of which is highly interesting, not only to the surgeon, but also to the non-professional read: er. Not very long ago, this distinguished surgeon was called to visit, in consultation, a young girl about 14 years of age, who, for more than six ycars, had suffered from involuntary movements in some of the muscles on the outer side of the leg. These movements were characterized by pulsations or knocks, having almost the regularity of a pulse, each knock being distinctly heardat some distance, as proceeding from behind the external malleolus. A similar affection manifested itself, not long after the first, at a corresponding point in the left leg, though less intense in degree. There was pain, hesitation, and tendency to fall when walking. When the foot was extended, and on applying pressure to certain points along the course of the muscles, the patient could for a time arrest the throbbing; but this invariably produced a good deal of pain and fatigue in the limb. The pareuts of the girl had 